\section{Effects of Pigment Constituents and Their Distribution on Spathe Coloration of Zantedeschia hybrida}

\author{
Ting Lei ${ }^{1}$ and Yang Song ${ }^{1}$ \\ Faculty of Modern Agricultural Engineering, Kunming University of Science \\ and Technology, Kunmming 650500, China
}

Xuehua Jin' ${ }^{2}$, Tianyu Su, and Yiwen Pu
Faculty of Architecture and City Planning, Kunming University of Science
and Technology, Kunming 650500, China

Additional index words. epidermal cells, stained cell layers, anthocyanins, flavonoids, black color mechanism

\begin{abstract}
The plant Zantedeschia hybrida is colorful and suitable for cut flowers and potted plants. This study employed a colorimetric method for the determination of spathe color phenotypes in $27 \mathrm{Z}$. hybrida cultivars and classified them into six major color classes. To characterize the coloration mechanism of the $Z$. hybrida spathe, this study explored the main colorants and pigment distribution using high-performance liquid chromatography (HPLC) with photodiode array detection (DAD) and electrospray ionization mass spectrometry (ESI-MS), ultra-performance liquid chromatography/ hybrid triple quadrupole linear ion trap mass spectrometry (UPLC-Q-TRAP-MS), and tissue sections. The results showed that flavonoids were colorants in the spathes of different color groups and that cyanidin $(\mathrm{Cy})$ was the main colorant, whereas carotenoids were not detected in the spathe. Total anthocyanin (TA) content was negatively correlated with lightness $\left(L^{*}\right)$ of coloration, such that a spathe with a higher TA and thicker pigmented cell layer showed a deeper color; however, there was no correlation between deep coloration in a spathe and flattened upper epidermal cells. The difference in TA was the main reason for the color variation among $Z$. hybrida of different color groups, whereas the total flavones and flavonols (TF) played a key role in the coloration of the orange and yellow group.
\end{abstract}

Flower colors are among the most adaptive phenotypes in plant evolutionary history; they provide an important basis for species classification and comprise a vital aspect of plant epigenetics (Deguchi et al., 2013; Sun et al., 2009). Flower coloration is affected by multiple factors such as pigment content and distribution in petals, the $\mathrm{pH}$ and metal ions of the pigmented cell sap, and petal epidermal cell structure (Dao et al., 2016; Jin et al., 2016; Li et al., 2014; Mol et al., 1998; Paech, 1955; Zhao et al., 2016). There are three main classes of pigments that contribute to flower color: flavonoids, carotenoids, and betalains (Griesbach, 2005). Anthocyanins are flavonoids that produce orange to blue-violet colors in flowers, whereas other flavonoids such as aurones and flavones render flowers light yellow or colorless (Mizuta et al., 2009; Zhao et al., 2004). Anthocyanins are generally distributed in epidermal cells,

Received for publication 16 June 2017. Accepted for publication 23 Oct. 2017.

The work was supported by the National Natural Science Foundation of China (No. 31560568; No. 31760587).

${ }^{1}$ These authors contributed equally to this work. ${ }^{2}$ Corresponding author. E-mail: xh_kimlian@126. com. analysis in 2003. However, because of the limitations of cultivar quantity and analytical technology, the mechanisms of spathe color formation are still currently unclear. Therefore, there is a need to collect more cultivars and use advanced technology to determine the composition and content of flavonoids and analyze the effects of microscopic structure on flower color, so as to further understand the mechanisms by which flower color is determined and to provide a basis for selection of superior parents to breed ideal colors at the same time.

In this study, we analyzed 27 Z. hybrid cultivars for their anthocyanin composition, content, and cross sections to resolve the relationship between the spathe color parameters of Z. hybrida and pigment composition and microstructure. Flower color phenotypes were defined and classified, and the metabolic pathway of anthocyanins in spathes was preliminarily deduced to provide a basis for understanding the coloration mechanism in spathes.

\section{Materials and Methods}

Plant materials. During a resource survey in Kunming area, the research group collected a total of $27 \mathrm{Z}$. hybrida cultivars (the main color groups in $Z$. hybrida were covered by all selected cultivars) mainly derived from the greenhouse of Kunming Trifecta orchid Nursery Co., Ltd. (lat. $24^{\circ} 33^{\prime} \mathrm{N}$, long. $\left.102^{\circ} 41^{\prime} \mathrm{E}\right)$, in May 2016. The cultivation conditions were as follows: $20^{\circ} \mathrm{C}$ with a $12 \mathrm{~h}$ photoperiod provided by incandescent lights and humidity of $30 \%$ (constant temperature and humidity). Plants showing the same growth pattern were selected, and fully opened spathes were collected for flower color determination, slice preparation, and pigment analysis.

Color analysis. The colors of the fresh spathe of the 27 variants were first compared with the Royal Horticultural Society Color Chart, and the surface color of the spathe was analyzed with a Chroma Meter CR-400 [Konica Minolta (China) Investment Ltd., Shanghai, China] at $C / 2$. Three spathe samples of each cultivar were taken from different plants. The $Z$. hybrida spathe was placed on clean white paper and the light source was aligned to the middle part of the spathe for measurement. Finally, using PASW Statistics 18 software, hierarchical clustering analysis was performed using phenotype values of spathe flower colors measured by colorimeter. The cluster analysis method using the furthest neighbor, coupled with CIElab color space data (Voss, 1992) was used to characterize spathe color.

Extraction of anthocyanins and TF. Zantedeschia hybrida spathes were quickly ground into fine powder in liquid nitrogen. After the liquid nitrogen was evaporated, $250 \mathrm{mg}$ of spathe powder was added to $1 \mathrm{~mL}$ of anthocyanin extraction solution [V (methanol) : V (water) : V (formic acid) : V $($ trifluoroacetic acid) $=70: 27: 2: 1]$. Total flavones and flavonols were extracted from $100 \mathrm{mg}$ of fresh sample with $1 \mathrm{~mL}$ of methanol as the extraction solution using 


\begin{tabular}{|c|c|c|c|c|c|c|}
\hline \multirow[b]{2}{*}{ Color group and cultivars } & \multirow[b]{2}{*}{ RHSCC } & \multicolumn{5}{|c|}{ CIELab coordinates } \\
\hline & & $L^{*}$ & $a^{*}$ & $b^{*}$ & $C^{*}$ & $h^{\circ}$ \\
\hline Mirages & N77A & 19.20 & 4.94 & 0.18 & 4.96 & 2.06 \\
\hline Cantor & N92A & 23.89 & 5.56 & -0.08 & 5.55 & -0.82 \\
\hline Black Girl & N187 & 20.77 & 6.58 & 0.10 & 6.58 & 0.80 \\
\hline Prado & N92 & 24.39 & 16.50 & -0.39 & 16.49 & -1.35 \\
\hline Lover & $71 \mathrm{~B}$ & 36.69 & 40.12 & -2.75 & 40.17 & -3.80 \\
\hline Promise & $22 \mathrm{~A}$ & 20.22 & 11.48 & 0.29 & 11.5 & 1.43 \\
\hline Picasso & $79 \mathrm{~A}$ & 28.46 & 24.91 & -6.37 & 25.58 & -19.0 \\
\hline Premio & N34 & 51.94 & -6.92 & 48.15 & 48.5 & 33.56 \\
\hline \multicolumn{7}{|l|}{ Red group } \\
\hline Durance & $44 \mathrm{~A}$ & 48.08 & 26.94 & 18.19 & 32.78 & 34.01 \\
\hline Figo & $53 \mathrm{D}$ & 31.99 & 45.46 & 13.53 & 47.57 & 16.65 \\
\hline Jin cheng & $6 \mathrm{~A}$ & 83.80 & -6.38 & 71.30 & 72.08 & 96 \\
\hline Blanc & $150 \mathrm{D}$ & 74.15 & -7.25 & 19.99 & 21.72 & 110 \\
\hline \multicolumn{7}{|l|}{ Pink group } \\
\hline Romance & $65 \mathrm{~B}$ & 71.37 & 7.76 & 3.17 & 8.57 & 22.19 \\
\hline Roseland & $27 \mathrm{~B}$ & 80.50 & 4.41 & 10.73 & 12.05 & 67 \\
\hline Melrose & 36B & 69.51 & 7.94 & 7.04 & 10.93 & 41 \\
\hline Ventura & N155D & 78.38 & -1.36 & 6.63 & 7.24 & 102 \\
\hline Jian ai & $55 \mathrm{C}$ & 70.47 & 17.13 & 2.99 & 17.47 & 9.89 \\
\hline \multicolumn{7}{|l|}{ Orange group } \\
\hline Phoenix & 17B & 74.22 & 5.1 & 79.36 & 80.02 & 86 \\
\hline Lido & N30D & 58.89 & 14.01 & 27.76 & 31.53 & 63 \\
\hline Odean & $32 \mathrm{~B}$ & 69.27 & 37.1 & 32.79 & 49.80 & 73.2 \\
\hline
\end{tabular}

Note: $L^{*}$ represents lightness, $a^{*}$ represents redness, $b^{*}$ represents yellowness, $C$ represents chroma, $C=\left(a^{* 2}+b^{* 2}\right)^{1 / 2}, h$ represents hue angle, $h=\arctan \left(b^{*} / a^{*}\right)$ (Gonnet, 1993).

RHSCC $=$ Royal Horticultural Society Color Chart.

the same processing method. Both extracts were incubated at $4{ }^{\circ} \mathrm{C}$ followed by a $24 \mathrm{~h}$ extraction, with vortexing every $12 \mathrm{~h}$ (Hashimoto et al., 2000; Jia et al., 2008; Yoshitama, 1981; Zhang et al., 2009). The extracts were filtered through a $0.2 \mu \mathrm{m}$ filter to obtain the samples to be tested.

Measurement of $T A$ and $T F$ and their structural identification. Total anthocyanin was measured using HPLC ( $\mathrm{Li}$ et al., 2008). TA was measured using an Agilent HPLC equipped with a P680 pump, UltiMate 3000 autosampler, DAD-100 ultraviolet-visible (ultraviolet-vis) detector, TCC-100 column oven and Agilent ZORBAX SB-Aq $(4.6 \mathrm{~mm} \times$ $250 \mathrm{~mm}$ ) column. For the HPLC measurements, the mobile phase consisted of solvents $\mathrm{A}$ and $\mathrm{B}$ (solvent $\mathrm{A}$ : water : formic acid : trifluoroacetic acid $=97.9: 2: 0.1$; solvent $\mathrm{B}$ : water : acetonitrile : formic acid : trifluoroacetic acid $=62.9: 35: 2: 0.1$ ). The mobile phase was subjected to ultrasonic degassing and $0.2 \mu \mathrm{m}$ ultrafiltration before injection. The injection volume was $10 \mu \mathrm{L}$, the column temperature was $25^{\circ} \mathrm{C}$, and the flow rate was $0.8 \mathrm{~mL} \cdot \mathrm{min}^{-1}$. The elution gradient profile of mobile phase B was $30 \%$ to $53 \%$ for $0-20 \mathrm{~min}, 53 \%$ to $53 \%$ for $20-40 \mathrm{~min}, 53 \%$ to $30 \%$ for $40-45 \mathrm{~min}$, and $30 \%$ to $30 \%$ for $45-50 \mathrm{~min}$. The peak areas of petal anthocyanin absorbance at a wavelength of $530 \mathrm{~nm}$ were determined (Jia et al., 2008).

For the HPLC-MS, HPLC-ESI-MS ${ }^{\mathrm{n}}$ was used to analyze the structure of anthocyanins in typical samples using the Agilent 6540QTOT liquid chromatography--mass spectrometry system. Liquid chromatography (LC) was performed based on the aforementioned conditions and procedures. Mass spectrometry (MS) conditions included ion trap analyzer scanning from m/z 100 to 1600 ; positive ionization mode with capillary voltage of $3500 \mathrm{~V}$; nebulizer pressure of 200 $\mathrm{kPa}$; capillary exit of $100 \mathrm{~V}$; dry temperature of $350{ }^{\circ} \mathrm{C}$; and drying gas $\left(\mathrm{N}_{2}\right)$ flow rate of $6.0 \mathrm{~L} \cdot \mathrm{min}^{-1}$ (Sun et al., 2010; Yamagishi et al., 2014). The mass spectra were analyzed using MZmine software (Okinawa Institute of Science and Technology, Okinawa, Japan).

TF was measured using an UPLC-QTRAP (Ultimate 3000-API 3200 Q TRAP) system (SCIEX, Redwood, CA) equipped with an MSLab HP-C18 (150 $\mathrm{mm} \times$ $4.6 \mathrm{~mm}, 5 \mu \mathrm{m})$ column. For the UPLC measurements, the mobile phase consisted of solvent A (water) and solvent B (acetonitrile), an injection volume of $10 \mu \mathrm{L}$, column temperature of $50{ }^{\circ} \mathrm{C}$, and flow rate of 1 $\mathrm{mL} \cdot \mathrm{min}^{-1}$.

Petal TA and TF were calculated in $\mu \mathrm{g} \cdot \mathrm{g}^{-1}$ fresh petal using a semiquantitative method (compared with standards) (Wang et al., 2001). The content of each compound with standards was calculated using the external standard method (TA: $y=0.00001 x-0.000, R^{2}=$ 0.999; TF: $y=0.00005 x-0.09369, R^{2}=0.998$ ).
The anthocyanin quantitative standard was $\mathrm{Cy}$, and the quantitative and qualitative standards for flavones and flavonols were naringenin, apigenin, luteolin, dihydromyricetin, dihydrokaempferol, dihydroquercetin, myricetin, kaempferol, and quercetin. The standards were purchased from Shanghai Yuanye Bio-Technology Co., Ltd. (Shanghai, China).

Extraction and measurement of carotenoids. Zantedeschia hybrida spathes $(100 \mathrm{mg})$ were ground in liquid nitrogen and added to $5 \mathrm{~mL}$ of extraction solution [V (petroleum ether) : $\mathrm{V}$ (acetone) $=1: 1]$ with thorough vortexing, followed by an $8 \mathrm{~h}$ overnight extraction in the dark (wrapped in aluminum foil) at $4{ }^{\circ} \mathrm{C}$. The extract was then filtered and the filtrate was subjected to ultraviolet-visible spectroscopy at a wavelength range of 400 $500 \mathrm{~nm}$ using a double-beam ultravioletvisible spectrophotometer (TU-1901; Beijing Persee General Instrument Co., Ltd., Beijing, China) (Zhao et al., 2004).

Observation of the spathe cross section of $Z$. hybrida. The center regions of $Z$. hybrida where spathes maintain even coloration were used for the preparation of plant slices (Rasika et al., 2003). The center cross section of the spathes was manually cut using a shaver blade and placed on a slide for observation using a light microscope (Digital Sight DS-Fi2; Nikon Corporation, Tokyo Japan); photographs were taken using an attached camera. 

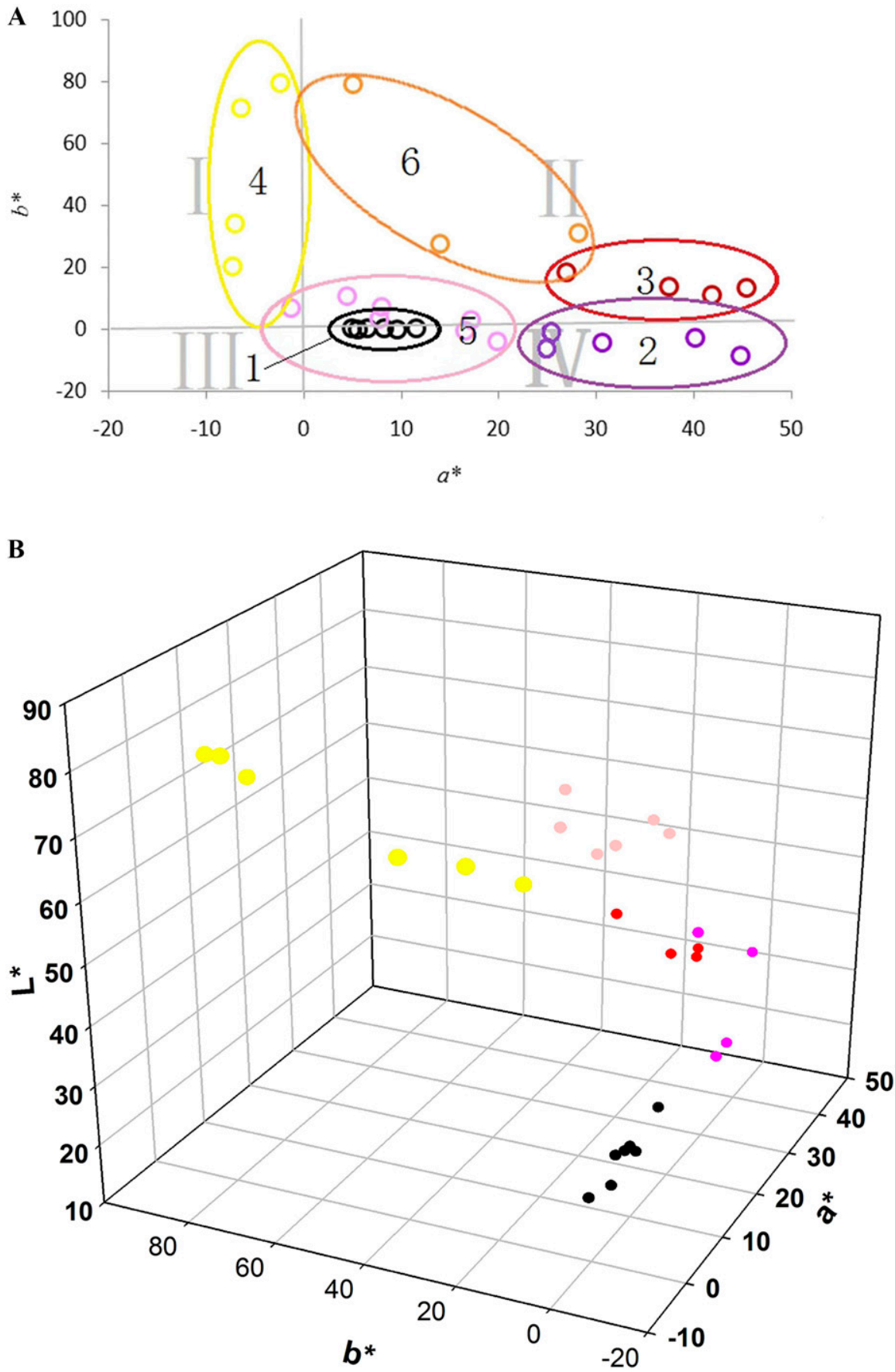

Fig. 1. Flower-color distribution of $Z$. hybrida cultivars in coordinate systems of bivariate $\left(a^{*}\right.$ and $\left.b^{*}\right)$ (A) and trivariate [lightness $\left(L^{*}\right), a^{*}$, and $\left.b^{*}\right](\mathbf{B})$, respectively. 1: black group; 2: amaranth group; 3: red group; 4: yellow group; 5: pink group; 6: orange group.

\section{Results}

Analysis of the spathe color phenotypes of different $Z$. hybrida cultivars. The CIE $L^{*}$, redness $\left(a^{*}\right)$, and yellowness $\left(b^{*}\right)$ values of $Z$. hybrida spathes with different colors were measured using colorimetry and the data were subjected to cluster analysis. The flower colors were divided into six groups based on the transition line graphs plotted for black, amaranth, red, yellow, pink, and orange groups (Table 1).

The spathe colors of the 27 Z. hybrida cultivars were mainly distributed in Quadrants
I, II, and IV on $a^{*}$ and $b^{*}$ hue coordinates, and no spathe color was distributed in Quadrant III of the blue area (Fig. 1A). The yellow group was distributed in Quadrant I, orange and red groups were distributed in Quadrant II, black and amaranth groups were mainly distributed in Quadrant IV, and the pink group was distributed in Quadrants I, II, and IV. The $a^{*}$ values (redness) ranged from -7.25 ('Blanc') to 45.46 ('Figo'); the $b^{*}$ values ("yellowness") ranged from -4.56 ('Promise') to 79.59 ('Solo'); the $h_{\mathrm{ab}}$ ("hue angle") ranged from $-19^{\circ}$ ('Picasso') to $110^{\circ}$ ('Blanc').
The three-dimensional coordinate distribution of the $L^{*}, a^{*}$, and $b^{*}$ values of the flower colors of each cultivar is shown in Fig. 1B. The $L^{*}$ values of black, amaranth, and red groups were lower than those of the pink, yellow, and orange groups with a concentrated distribution. Among them, the black group had the lowest $L^{*}$ value, whereas the pink and yellow groups had the highest $L^{*}$ values. The $L^{*}$ values ranged from 19.20 ('Mirages') to 83.80 ('Solo'); the $C$ values (chroma) ranged from 1.53 ('Cantor') to 80.02 ('Solo').

Different color groups of $Z$. hybrida have different relationships between $L^{*}$ and $C$ (Fig. 2). There was a significant positive relationship between $C$ values and $L^{*}$ values in the orange, yellow, and black groups $\left(r^{2}=\right.$ $0.552, r^{2}=0.845$, and $r^{2}=0.546$, respectively), where the $L^{*}$ increased linearly with the increase in $C$. On the contrary, there was a significant negative correlation between the $C$ value and the $L^{*}$ values in the red group $\left(r^{2}=0.904\right)$, where the $L^{*}$ decreased linearly with the increase in $C$. No significant relationship was found for $C$ values and $L^{*}$ values in the amaranth and pink groups $\left(r^{2}=\right.$ 0.0123 , and $r^{2}=0.228$, respectively) (Supplemental Fig. 1).

Analysis of pigment composition and content in Z. hybrida spathe. Spathe anthocyanins in $Z$. hybrida were identified using HPLC-PAD to obtain the HPLC chromatogram of different color groups. The type of anthocyanin can be determined depending on the retention time of the anthocyanin peak (Yasuda, 1989a, 1989b). Two types of anthocyanins were detected from the results, namely A 1 and A2, with retention times of 26 and $28 \mathrm{~min}$, respectively. No anthocyanin absorption peak was detected in the yellow group or for 'Ventura' in the pink group (Fig. 3).

The mass spectra of anthocyanins showed that their molecular ions often carry a hydrogen ion and are present in the form of $[\mathrm{M}+\mathrm{H}]^{+}$. Anthocyanins were mainly classified based on the mass-to-charge ratio of glycoside ions $\left[Y_{0}\right]^{+}$in their mass spectra (Beatriz et al., 2009; Cuyckens and Claeys, 2004; Stobiecki, 2000). In this study, we performed an MS analysis on these two types of anthocyanins (Supplemental Fig. 2). The molecular ions at $\mathrm{m} / \mathrm{z} 595\left[(\mathrm{M}+\mathrm{H})^{+}\right]$were obtained from A1, which produced the characteristic fragment ions of $\mathrm{Cy}$ at $\mathrm{m} / \mathrm{z}$ $287\left[\left(\mathrm{Y}_{0}\right)^{+}\right]$and other fragment ions at $\mathrm{m} / \mathrm{z}$ 449. The molecular ions at $\mathrm{m} / \mathrm{z} 595[(\mathrm{M}+$ $\mathrm{H})^{+}$] were obtained from A2, which produced the characteristic fragment ions of pelargonidin $(\mathrm{Pg})$ at $\mathrm{m} / \mathrm{z} 271\left[\left(\mathrm{Y}_{0}\right)^{+}\right]$and of other fragment ions at $\mathrm{m} / \mathrm{z} 433$. Hence, it was inferred that $\mathrm{A} 1$ was $\mathrm{Cy}$ and that $\mathrm{A} 2$ was $\mathrm{Pg}$. The common component in the spathe of all color groups, except for the yellow group, was A1 (Cy). It was also the main anthocyanin component in $Z$. hybrida spathes. By contrast, A2 (Pg) was mainly found in certain cultivars of red and orange groups ('Murano', 'Trinity', 'Durance', and 'Lido'). 


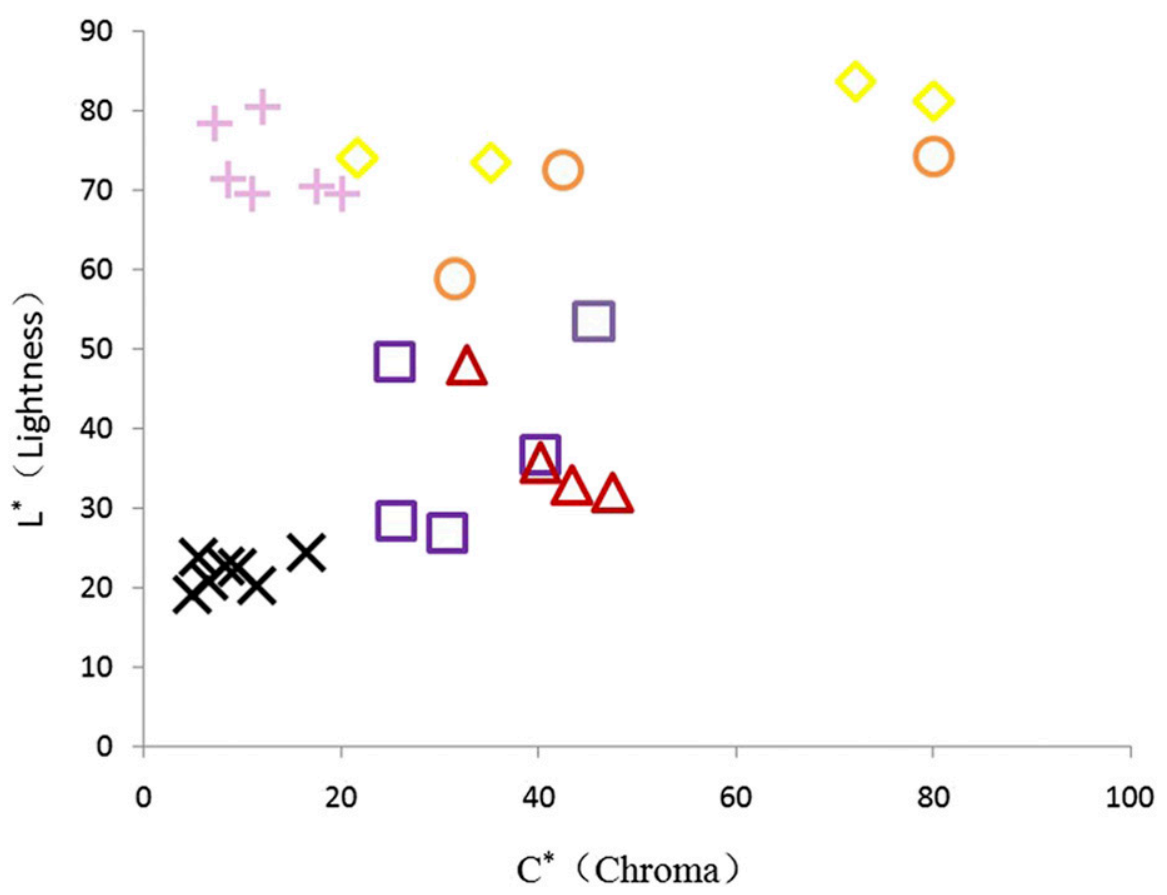

Fig. 2. Scatterplot based on lightness $\left(L^{*}\right)$ and $C$ values among $Z$. hybrida cultivars. $\times$ : black group; $\square$ : amaranth group; $\Delta$ : red group; $\diamond$ : yellow group; +: pink group; $\bigcirc$ : orange group.
The black group had a significantly higher spathe TA than the other color groups (Table 2; Fig. 4), followed by the amaranth, red, orange, and pink groups, and the TA content in each flower color group was highly significantly different $(P<0.01)$ (Table 3$)$. 'Murano' had the highest proportion of $\mathrm{Pg}$ (38.5\%) among four cultivars containing both $\mathrm{Cy}$ and Pg. All 27 cultivars were rich in TF with a copigmentation index (CI) that ranged from 8.12 to 989.06 (Table 2). The TF content in each flower color group was significantly different $(P<0.05)$ (Table 4).

UPLC-Q-TRAP-MS was used to analyze the composition of flavones and flavonols in the spathes of two cultivars ('Romance' and 'Black Girl'). Ten peaks from primary MS data were found to be associated with flavones and flavonols using comparison of standards. Comparison of the total ion chromatogram of spathe samples and standard total ion chromatogram (Supplemental Fig. 3) indicated that the samples from the two cultivars contained naringenin, luteolin, myricetin, dihydromyricetin, dihydrokaempferol, dihydroquercetin, kaempferol, quercetin, catechins, and epicatechin. Quantitative analysis using standards was performed (Table 5).
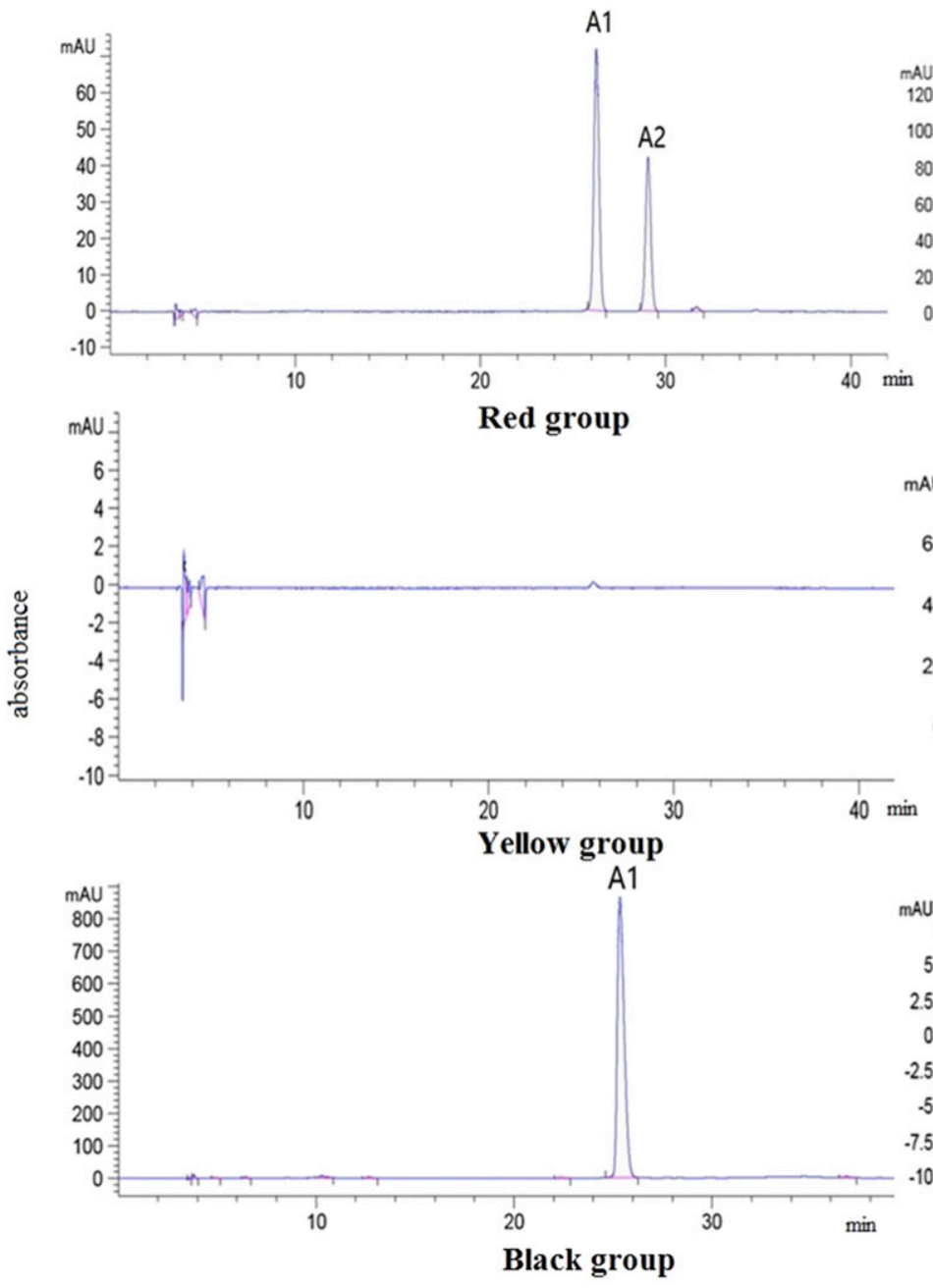

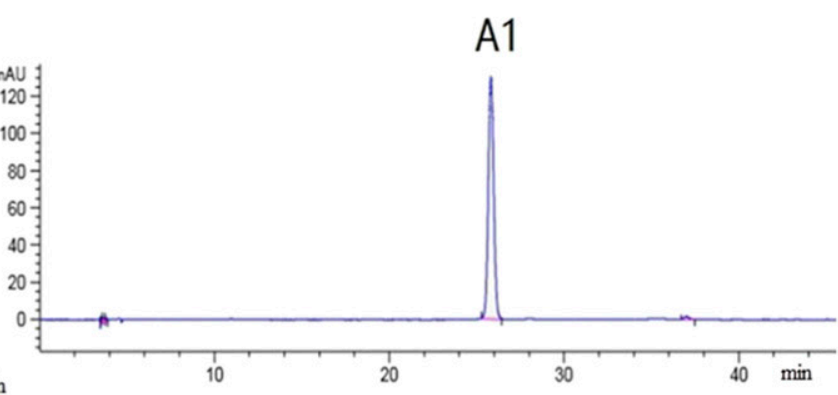

Amaranth group

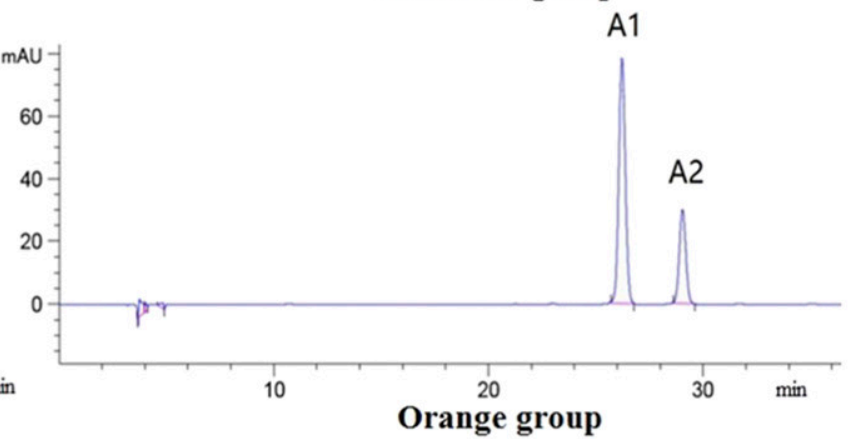

A1

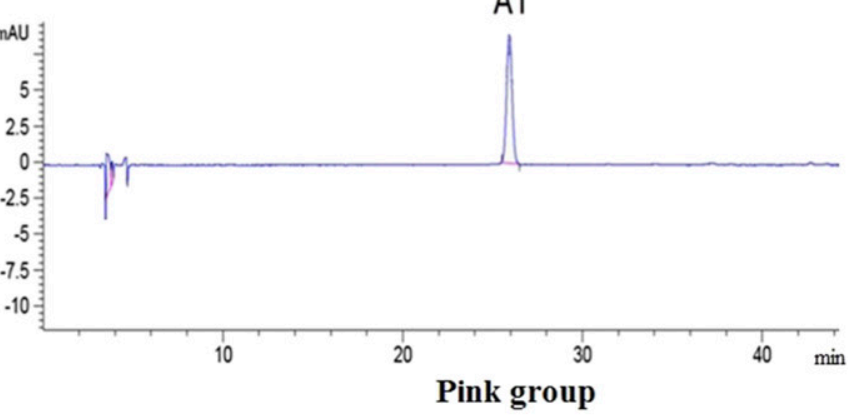

Retention time

Fig. 3. The anthocyanin HPLC profiles of the main flower color in Z. hybrid (detected at $530 \mathrm{~nm}$ ). 
Table 2. Pigment constitutions and relative quantity of anthocyanins in 27 Z. hybrida cultivars.

\begin{tabular}{|c|c|c|c|c|c|}
\hline Color group and cultivars ${ }^{2}$ & $\mathrm{Cy}^{\mathrm{y}}(\%)$ & $\operatorname{Pg}^{y}(\%)$ & $\mathrm{TA}^{\mathrm{x}}\left(\mu \mathrm{g} \cdot \mathrm{g}^{-1}\right)$ & $\mathrm{TF}^{\mathrm{x}}\left(\mu \mathrm{g} \cdot \mathrm{g}^{-1}\right)$ & $\mathrm{CI}^{\mathrm{x}}$ \\
\hline \multicolumn{6}{|l|}{ 1. Black group } \\
\hline Jack & 100 & - & 617.2 & $8,362.0$ & 13.5 \\
\hline Chocolate & 100 & - & 546.0 & $7,013.3$ & 12.8 \\
\hline Black Girl & 100 & - & $1,179.8$ & $9,583.3$ & 8.1 \\
\hline Prado & 100 & - & 665.3 & $7,749.3$ & 11.6 \\
\hline \multicolumn{6}{|l|}{ 2. Amaranth group } \\
\hline Promise & 100 & - & 208.9 & $4,312.7$ & 20.6 \\
\hline Picasso & 100 & - & 100.3 & $3,775.3$ & 37.3 \\
\hline Premio & 100 & - & 164.0 & $4,668.6$ & 28.5 \\
\hline \multicolumn{6}{|l|}{ 3. Red group } \\
\hline Durance & 88 & 12.0 & 32.4 & $5,360.0$ & 165.4 \\
\hline Figo & 100 & - & 75.5 & $6,916.6$ & 91.67 \\
\hline Murano & 61.5 & 38.5 & 104.1 & $3,185.0$ & 30.59 \\
\hline Blanc & - & - & - & $8,237.2$ & $\infty$ \\
\hline \multicolumn{6}{|l|}{ 5. Pink group } \\
\hline Romance & 100 & - & 14.3 & $4,548.6$ & 319.0 \\
\hline Roseland & 100 & - & 7.4 & $7,299.3$ & 989.1 \\
\hline Melrose & 100 & - & 5.7 & $1,086.2$ & 189.6 \\
\hline Ventura & - & - & - & 772.5 & $\infty$ \\
\hline Jian ai & 100 & - & 20.8 & $4,450.8$ & 214.0 \\
\hline \multicolumn{6}{|l|}{ 6. Orange group } \\
\hline Phoenix & 100 & - & 5.8 & $4,457.4$ & 768.5 \\
\hline Lido & 71.5 & 28.5 & 74.2 & $4,312.7$ & 58.1 \\
\hline Odean & 100 & - & 65.1 & $4,201.0$ & 64.5 \\
\hline
\end{tabular}

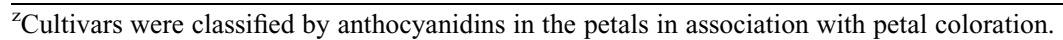

${ }^{\mathrm{y}} \mathrm{Cy}=$ cyanidin; $\mathrm{Pg}=$ pelargonidin. Data are expressed as percentage; $-=$ not detected.

${ }^{\mathrm{x}} \mathrm{TA}=$ total anthocyanins; $\mathrm{TF}=$ total flavones and flavonols; $\mathrm{CI}=$ copigmentation index; $\mathrm{CI}=\mathrm{TF} / \mathrm{TA} . \infty$ : mean samples without glycosides of anthocyanin.

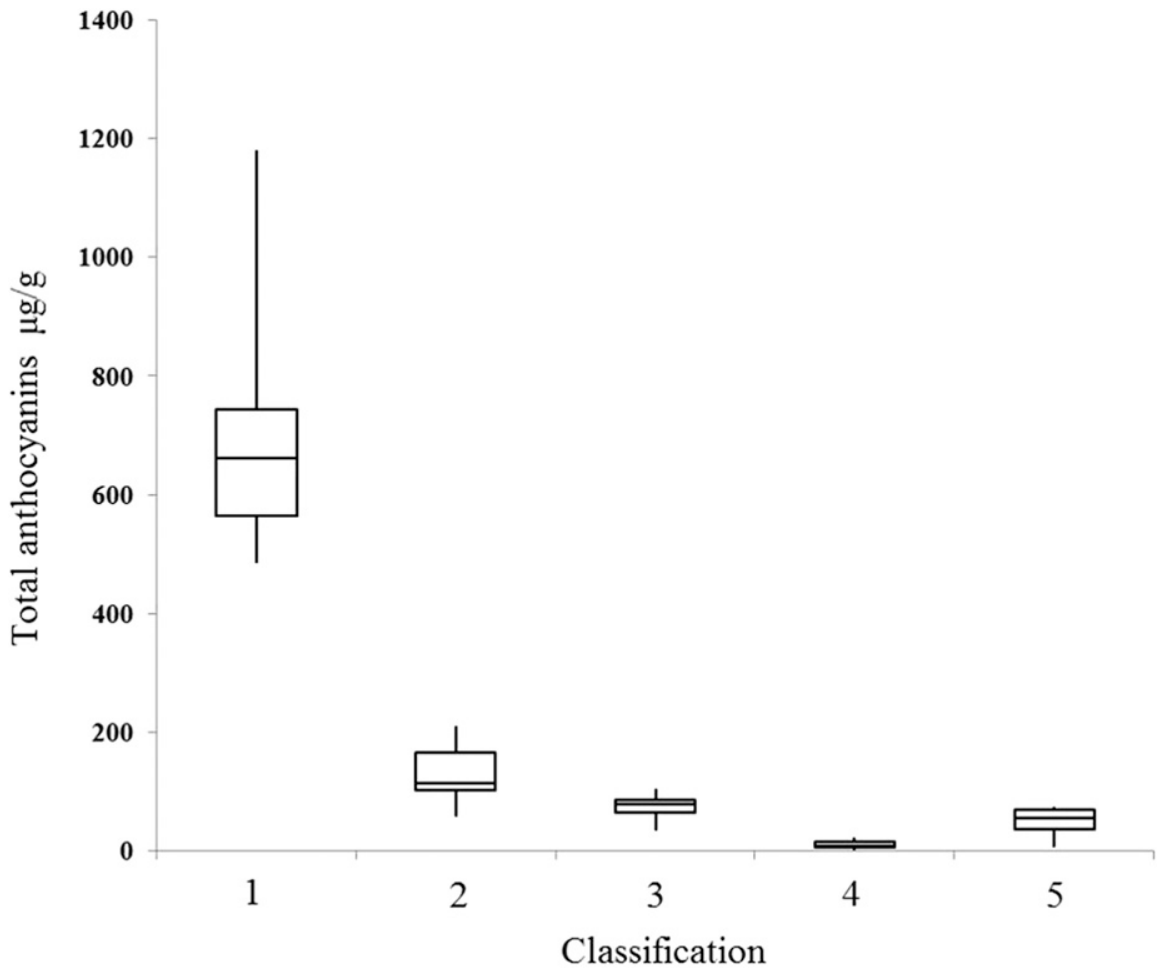

Fig. 4. Box plot of different color group of Z. hybrid cultivars based on total anthocyanins 1: black group; 2 : amaranth group; 3: red group; 4: pink group; 5: orange group.

Measurement of the spathe carotenoid extract using ultraviolet-visible spectrometry indicated that none of the $27 \mathrm{Z}$. hybrida cultivars showed the characteristic absorption peak at wavelengths of $400-500 \mathrm{~nm}$, indicating the absence of carotenoids in the Z. hybrida spathe.
Analysis of microstructure and pigment distribution in the $Z$. hybrida spathe. Analysis of the cross sections of the spathes of different $Z$. hybrida color groups showed that the spathe had flattened upper and lower epidermal cells, and that pigments were distributed in both upper and lower epidermal cells and mesophyll cells. In addition, spathes of different color groups had different numbers of stained cell layers, and spathes with a thicker stained cell layer had a deeper color (Fig. 5). Pigments of the black group were richly distributed in epidermal and mesophyll cells, and in the two to three layers of mesophyll cells close to both upper and lower epidermis. In the amaranth group, the pigments were distributed in the epidermal cells and the two layers of mesophyll cells; the lower epidermal cells and mesophyll cells close to the lower epidermis presented reduced accumulation compared with the upper epidermal cells. In the red and orange groups, pigments were distributed in the epidermal cells and a single layer of mesophyll cells. In the pink group, pigments were present only in the epidermal cells. Anthocyanins were not found in the yellow group or in 'Ventura' of the pink group. Thus, spathe coloration in $Z$. hybrida was closely associated with pigment distribution in the spathe.

\section{Discussion}

Correlation among spathe color parameters in Z. hybrida. This study performed a hierarchical 
Table 3. The analysis of variance analysis of the content of total anthocyanin among six flower color group of $Z$. hybrida.

\begin{tabular}{lcrccr}
\hline Variation source & SS & DF & MSS & $F$ & $F_{0.01}$ \\
\hline Among class & $1,909,120.7$ & 5 & $381,824.14$ & 29.73 & 4.042 \\
Inner class & $269,711.4$ & 21 & $12,843.4$ & & \\
Total & $2,178,832.1$ & 26 & & & \\
\hline
\end{tabular}

$\mathrm{SS}=$ square sum $; \mathrm{DF}=$ degree of freedom; $\mathrm{MSS}=$ mean square sum $F=$ mean square sum among class mean square sum inner class; $F_{0.01}=$ the threshold value of $F$ at 0.01 .

Table 4. The analysis of variance analysis of the content of TF among six flower color group of $Z$. hybrida.

\begin{tabular}{lrrrcr}
\hline Variation source & \multicolumn{1}{c}{ SS } & DF & MSS & $F$ & $F_{0.01}$ \\
\hline Among class & $65,306,474.59$ & 5 & $13,061,294.8$ & 2.74 & 2.68 \\
Inner class & $100,129,569.60$ & 21 & $4,768,074.71$ & & \\
Total & $165,436,044.20$ & 26 & & & \\
\hline
\end{tabular}

$\mathrm{SS}=$ square sum; $\mathrm{DF}=$ degree of freedom; MSS = mean square sum; $F=$ mean square sum among class/ mean square sum inner class; $F_{0.01}=$ the threshold value of $F$ at 0.01 .

Table 5. The composition and content of flavones and flavonols in 'Black girl' and 'Romance'.

\begin{tabular}{lrr}
\hline Cultivars flavonoids $\left(\mu \mathrm{g} \cdot \mathrm{g}^{-1}\right)$ & Romance & Black girl \\
\hline Naringenin & 0.80 & 4.60 \\
Luteolin & 3.0 & 0.0 \\
Myricetin & 75.7 & 41.2 \\
Dihydromyricetin & 48.9 & 495.0 \\
Dihydrokaempferol & 234.0 & $1,370.0$ \\
Dihydroquercetin & 17.2 & 40.4 \\
Kaempferol & $1,660.0$ & $2,540.0$ \\
Quercetin & 21.9 & 163.0 \\
Catechin & 255.0 & $1,070.0$ \\
Epicatechin & 351.0 & $5,320.0$ \\
\hline
\end{tabular}

analysis of flower color phenotypes $L^{*}, a^{*}$, and $b^{*}$, and established a measurement system for defining and classifying the flower color of $Z$. hybrida. The 27 collected cultivars were classified into six major color systems. When drawing the various color systems of $Z$. hybrida on the twodimensional hue $a, b$ coordinate scatter plot, we found that the yellow-color group was mainly distributed at 90 degrees around the coordinates, whereas the red-, black-, pink-, and amaranth-color groups were distributed at zero degrees around the coordinates, and the orange-color group was distributed at the second quadrant of the coordinates. This is generally consistent with the definition and distribution of colors in the CIElab color space (Voss, 1992), proving that the definition and classification of $Z$. hybrida flower colors in this study are scientific and reasonable.

Different Z. hybrida color groups had different relationships between $L^{*}$ and $C$. $L^{*}$ values and $C$ values of orange and yellow groups had a significant positive relationship, whereas the red group had a significant negative relationship. The linear regressions in the black, amaranth, and pink groups were nonsignificant. In previous studies, some color groups of Chrysanthemum morifolium cultivars (Hong et al., 2012) and some color groups of Consolida ajacis cultivars (Hashimoto et al., 2000) showed a significant negative relationship with the $L^{*}$ and $C$ values. The differences in the correlation between $L^{*}$ and $C$ values may be due to differences in anthocyanin compositions and distribution, as well as differ- ent petal cross-sectional structures in different cultivars

Relationship between the main pigments and phenotypes in Z. hybrida. The flower color is an important ornamental trait of plants (Nielsen et al., 2003). This study identified spathe anthocyanins in $27 \mathrm{Z}$. hybrida cultivars and found that the yellow group and 'Ventura' of the white group did not contain anthocyanins. Cultivars of all other color groups contained anthocyanins with $\mathrm{Cy}$ as the main component, whereas $\mathrm{Pg}$ only accumulated in four cultivars. Cy produced varying degrees of amaranth coloration of the spathe, similar results have been obtained in previous studies (He et al., 2011), whereas Pg produced varying degrees of vermilion color. According to a study of Papaver nudicaule, $\mathrm{Pg}$ is also an important coloring material that makes the petals red and orange (Bettina et al., 2016). The flavonoid composition of typical Araceae plants is relatively simple (Williams et al., 1981); for the $Z$. hybrida cultivars tested in this study, there was only one anthocyanin in 18 cultivars, and only two anthocyanins were found in the four cultivars. Anthocyanin was not detected in other cultivars, and carotenoids were not detected in any cultivars. Therefore, we believe that $\mathrm{TF}$ was the main pigment type producing yellow and orange colors. However, Lewis et al. (2003) found accumulation of carotenoids in cultivars of yellow and orange groups, possibly as the result of differences among cultivars. Flavones and flavonols are important copigments that exert their copigmentation effects when the CI exceeds 5 (Asen et al., 1971). In this study, the CI values of all tested cultivars were greater than 5 , indicating that flavones and flavonols play a relatively greater role in the coloration of Z. hybrida.

Previous studies have demonstrated that petal anthocyanins affect light absorption (Hughes et al., 2006; Merzlyak et al., 2008). The study of the relationship between the spathe phenotype and TA in Z. hybrida revealed a significant negative relationship between TA and $L^{*}$ value $\left(r^{2}=0.615\right)$ (Fig. 6), i.e., large amounts of TA decreased the $L^{*}$ values. The pink $\left(r^{2}=0.849\right)$, red $\left(r^{2}=\right.$ $0.667)$, and orange $\left(r^{2}=0.511\right)$ (Supplemental Fig. 4) color groups showed significant positive relationship between $a^{*}$ value and TA, demonstrating that TA content in these color groups is closely associated with redness. The $b^{*}$ value and TF value and the orangecolor group showed a significant positive relationship $\left(r^{2}=0.766\right)$ (Supplemental Fig. 4), suggesting that the formation of the orange-color group resulted from the combined effects of TA and TF. In previous studies on $Z$. hybrida (Lewis et al., 2003 ), the test materials were relatively uniform (orange, red, and pink color groups), and the $L^{*}$ values were distributed from 28.4 to 89.5 , the $h$ values were distributed from $35^{\circ}$ to $359^{\circ}$, and the TA concentration was $\approx 0-24 \mu \mathrm{g} \cdot \mathrm{g}^{-1}$. In the test materials in this study, the $L^{*}$ values were distributed around 19.2-83.8, $h$ values were $\approx 0.2^{\circ}$ to $110^{\circ}$, and TA content was $\approx 0-1179.8 \mu \mathrm{g} \cdot \mathrm{g}^{-1}$, which basically covered all existing major $Z$. hybrida color groups and cultivars and meant that we systematically analyzed the relationship between the type and content of anthocyanins and flower color phenotypes.

Black color in flowers is a highly attractive trait in the floricultural industry. Flower color shows species specificity and black flowers in different species have different coloring mechanisms. Dahlia flowers are presented as black generally because of low $L^{*}$ and low $C$ (Deguchi et al., 2013, 2015). The black cultivars collected in our study also have low $L^{*}$ and $C$ values. The petals of black Dahlia cultivars accumulated large amounts of anthocyanins (Deguchi et al., 2013). Similarly, the black cultivars in our study also showed the largest accumulation of anthocyanin content $\left(1179.8 \mu \mathrm{g} \cdot \mathrm{g}^{-1}\right)$. In addition, TA content in the spathes of 27 cultivars showed a significant negative relationship with $L^{*}$ values, i.e., when $L^{*}$ values were reduced to present a black phenotype, TA was an important factor. The main reason for black Alcea rosea 'Nigra' presenting as a black flower is the copigmentation of flavonols and flavones and accumulation of large amounts of anthocyanins (Hosaka et al., 2012). In the six black cultivars collected in this study, in addition to extensive accumulation of anthocyanins, flavonols and flavones accumulated in large amounts at the same time, and copigmentation may thus play some role in black coloration.

To further analyze the causes of the formation of the black group, this study compared the intermediate metabolites of flavonoids in 'Black Girl' of the black group and 'Romance' of the pink group, and characterized the metabolic pathway of anthocyanins in both cultivars (Fig. 7A and B). The amount of intermediate metabolites in both cultivars varied greatly (Table 5), with significantly higher amounts in 'Black Girl' than in 'Romance'. In addition, 'Black Girl' cultivars did not accumulate flavones, 

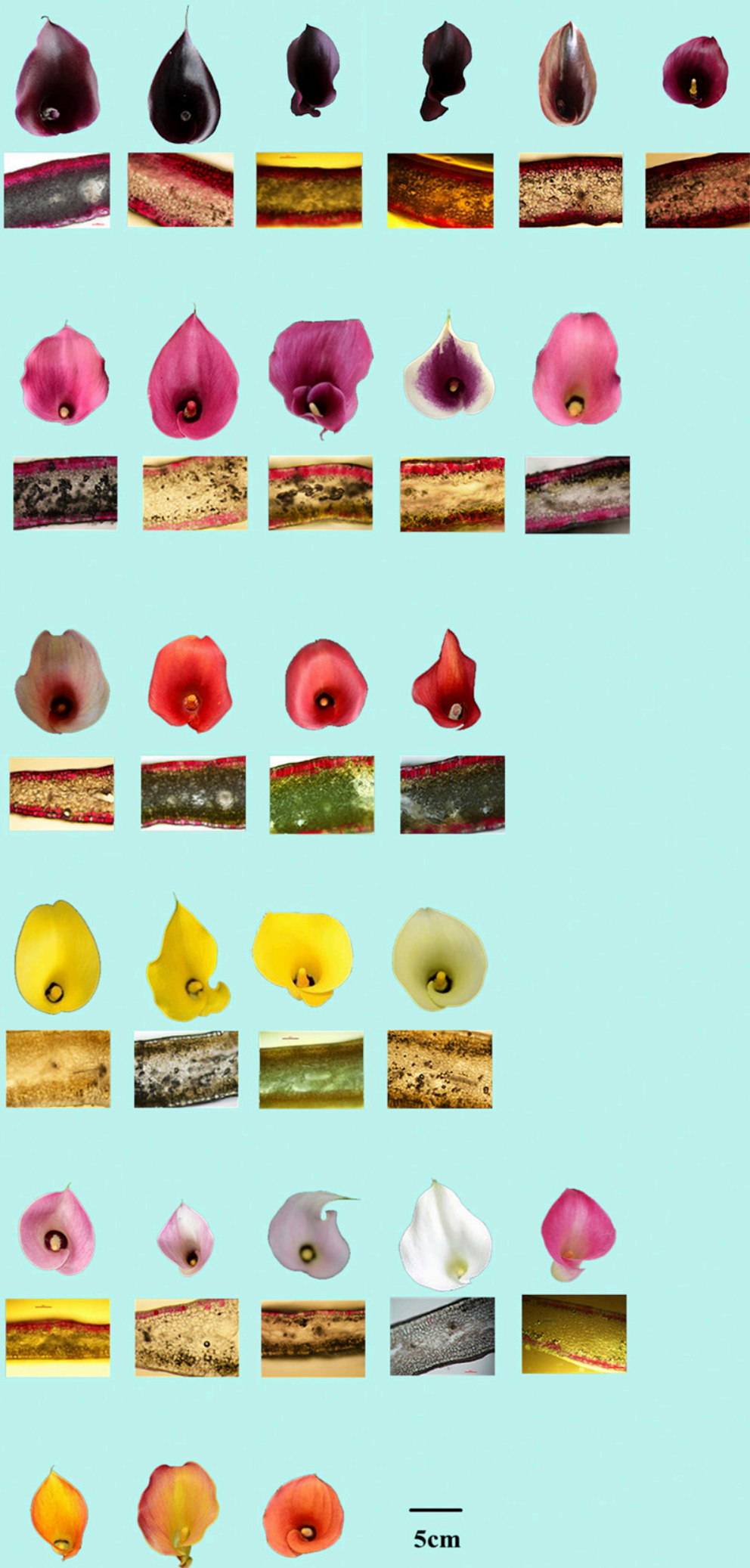

$5 \mathrm{~cm}$
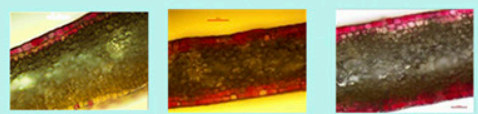

possibly because of the inhibition of FNS expression in 'Black Girl' that leads to inhibition of flavone synthesis as a result of competition with anthocyanins synthesis, thereby resulting in high accumulation of anthocyanins. This result was similar to that previously reported in Dahlia (Deguchi et al., 2013). Dihydromyricetin and myricetin were detected in both cultivars, which suggests that F3' $5^{\prime} \mathrm{H}$ may exist in $Z$. hybrida. However, these plants were incapable of accumulating delphinin to produce a blue coloration. This result requires further study.

Relationship between colorant distribution in the Z. hybrida spathe and phenotype. When light shines on the petals to penetrate the pigment layer, a higher number of pigment layers lead to higher light absorption and the proportion of incident light entering the cells increases, resulting in a deeper flower color (Gorton and Vogelmann, 1996; Noda et al., 1994; Rasika et al., 2003). It was found in this study that colorants were distributed in the upper and lower epidermal cells, as well as in multiple layers of mesophyll cells near the epidermal cells (palisade and spongy tissues) of the $Z$. hybrida spathe. In addition, cultivars of different color groups had different numbers of pigmented cell layers; a spathe with a thicker pigmented layer had a deeper color and the black group had the thickest pigmented cell layer. This is similar to the effects of pigment distribution in grape hyacinth on coloring (Qi et al., 2013). Cross-sectional structural observation indicated that the flavones and flavonols that cause yellow flower coloration are mainly distributed in the mesophyll cells of spathes, which is a different cell layer from where anthocyanins are distributed. This resulted in a background effect, particularly in orange coloration of spathes.

The shape of the petal epidermal cells affects the optical properties of the anthocyanin they contain, thereby affecting the appearance of the petals. Most angiosperms have conical petal upper epidermal cells that enhance the proportion of incident light entering the epidermal cells and the light absorption by pigments, thereby increasing the color intensity of the flower (Baumann et al., 2007). However, analysis of the microstructure of the spathes of the 27 cultivars examined in this study indicated that their epidermal cells did not have a conical shape, but rather a flattened shape, which resulted in greater light reflection that reduced the color intensity of the flowers (Gorton and Vogelmann, 1996). Therefore, the shape of the spathe epidermal cells was unrelated to the formation of the black $Z$. hybrida group. Conical epidermal cells can enhance color saturation (Baumann et al., 2007), whereas the flattened spathe epidermal cells of $Z$. hybrida reduce color saturation, which may be the main reason for the absence of correlation among $C$ value, TA, and TF in this study.

In conclusion, the coloration of the $Z$. hybrida spathe is closely associated with its pigment components and contents as well as the cross-sectional structure of the spathe. The formation of the $Z$. hybrida spathe in the 


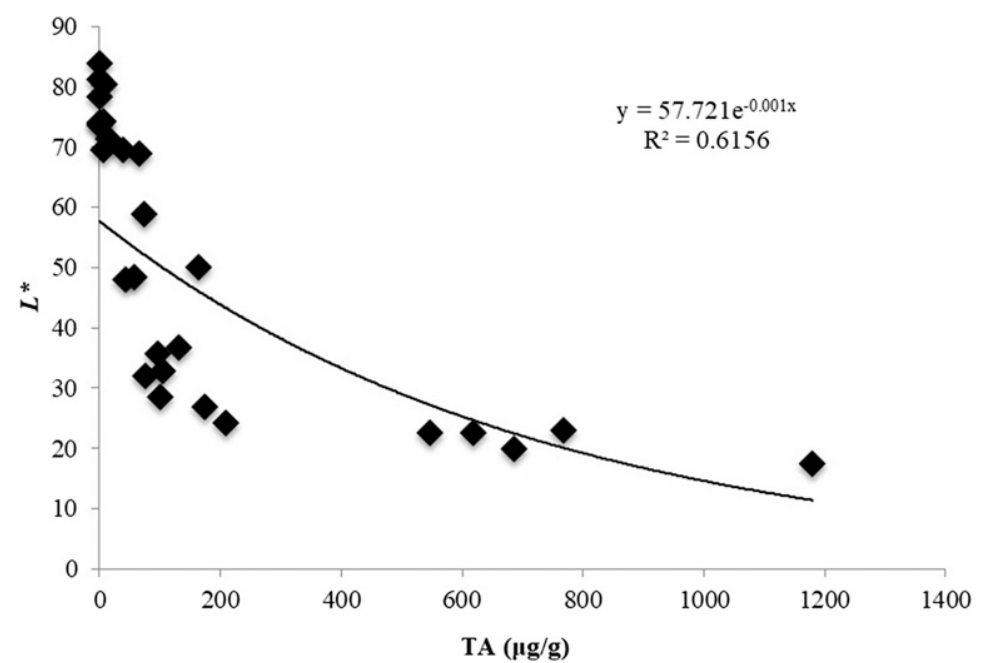

Fig. 6. Relationship between $L^{*}$ and total anthocyanins (TA) in Z. hybrida cultivars of different color groups.
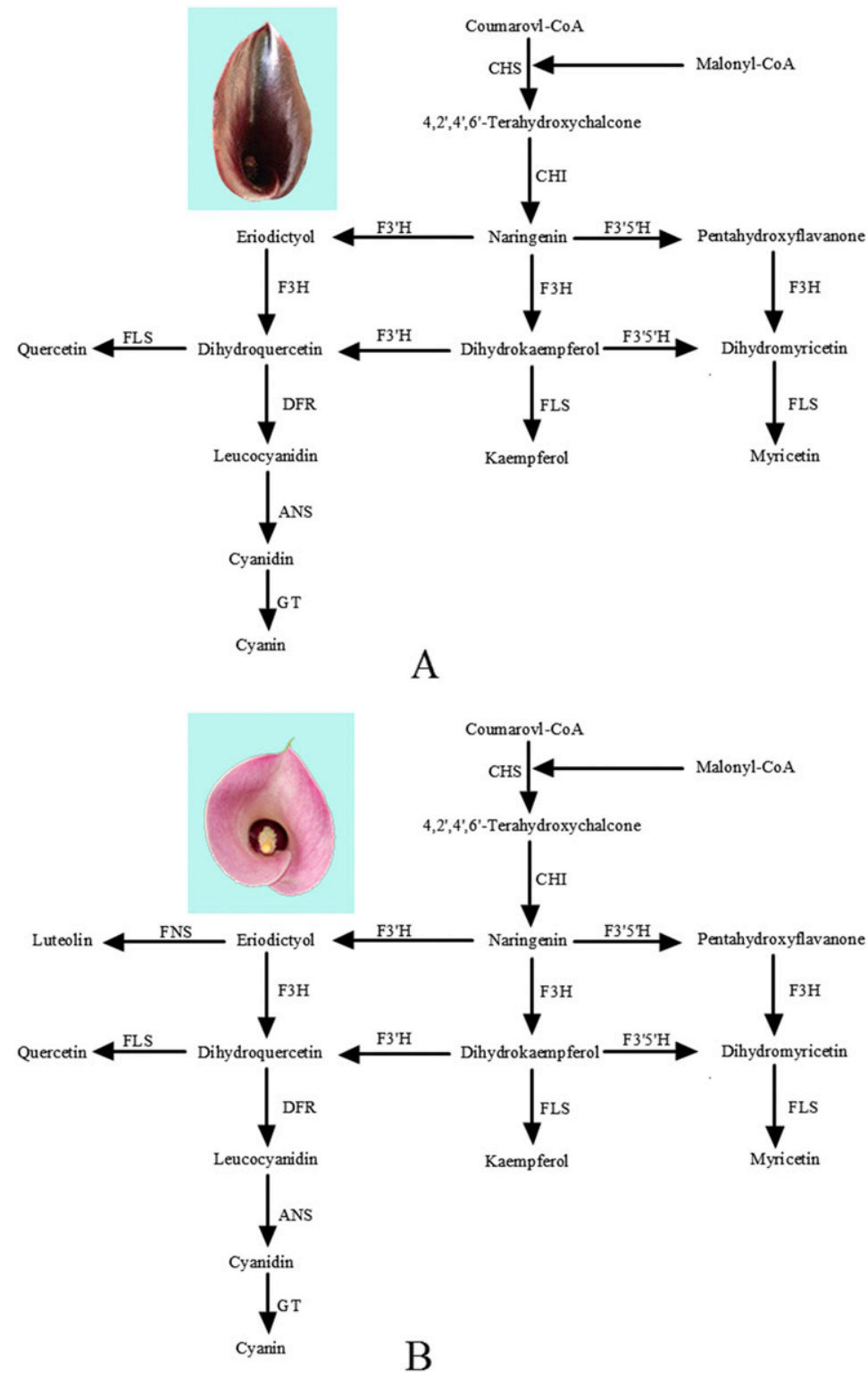

Fig. 7. Inferred metabolic pathways of anthocyanins in Z. hybrida spathe. (A) 'Black girl'; (B) 'Romance'. black group was closely associated with high TA and accumulation of anthocyanins in multiple cell layers, and was not correlated with the shape of epidermal cells. Analysis of the relationship between the coloration of $Z$. hybrida and its pigment compositions, contents, and distribution is important for resolving the coloration mechanism of the $Z$. hybrida spathe and for molecular breeding to improve the color of the flowers.

\section{Literature Cited}

Asen, S., R.N. Stewart, and K.H. Norris. 1971. Copigmentation effect of quercetin glycosides on 304 absorption characteristics of cyanidin glycosides and color of Red Wing Azalea. Phytochemistry 10(1):171-175.

Baumann, K., R.M. Perez, D. Bradley, J. Venail, P Bailey, H. Jin, R. Koes, K. Roberts, and C. Martin. 2007. Control of cell and petal morphogenesis by R2R3 myb transcription factors. Development 134(9):1691-1701.

Beatriz, A.G., L.A. Berrueta, S. Garmón-Lobato, B. Gallo, and F. Vicente. 2009. A general analytical strategy for the characterization of phenolic compounds in fruit juices by highperformance liquid chromatography with diode array detection coupled to electrospray ionization and triple quadrupole mass spectrometry. J. Chromatogr. A 1216(28):5398-5415.

Bettina, D., A.C. Warskulat, and B. Schneider. 2016. The occurrence of flavonoids and related compounds in flower sections of Papaver nudicaule. Plants 5(2):28.

Burchi, G., D. Prisa, A. Ballarin, and P. Menesatti. 2010. Improvement of flower color by means of leaf treatments in lily. Scientia Hort. 125(3): 456-460.

Cuyckens, F. and M. Claeys. 2004. Mass spectrometry in the structural analysis of flavonoids. J. Mass Spectrom. 39(1):1-15.

Dao, T.T.H., K. Ureshino, D.T. Van, and I. Miyajima 2016. Co-pigmentation of anthocyanin-flavonol in the blotch area of Rhododendron simsii planch flowers. Jpn. Soc. Hort. Sci. 85(3):232-237.

Deguchi, A., S. Ohno, M. Hosokawa, F. Tatsuzawa and M. Doi. 2013. Endogenous post-transcriptional gene silencing of flavone synthase resulting in high accumulation of anthocyanins in black dahlia cultivars. Planta 237:1325-1335.

Deguchi, A., F. Tatsuzawa, M. Hosokawa, M. Doi, and S. Ohno. 2015. Tobacco streak virus (strain dahlia) suppresses post-transcriptional gene silencing of flavone synthase II in black dahlia cultivars and causes a drastic flower color change. Planta 242(3):663-675.

Gonnet, J.F. 1993. CIElab measurementa precies communication in flower color: An example with carnation (Dianthus caryophyllus) cultivars. J. Hort. Sci. 68(4):499-510

Gorton, H.L. and T.C. Vogelmann. 1996. Effects of epidermal cell shape and pigmentation on optical properties of Antirrhinum petals at visible and ultraviolet wavelengths. Plant Physiol. 112:879-888.

Griesbach, R.J. 2005. Biochemistry and genetics of flower color. Plant Breed. Rev. 25:89-114.

Hashimoto, F., M. Tanaka, H. Maeda, K. Shimizu, and Y. Sakata. 2000. Characterization of cyanic flower color of Delphinium cultivars. J. Jpn. Soc. Hort. Sci. 69(4):428-434.

He, Q.L., Y. Shen, M.X. Wang, M.R. Huang, R.Z. Yang, S.J. Zhu, L.S. Wang, Y.J. Xu, and R.L. Wu. 2011. Natural variation in petal color in Lycoris longituba revealed by anthocyanin components. PLoS One 6(8):e22098. 
Hong, Y., X.X. Bai, W. Sun, F.W. Jia, and S.L. Dai. 2012. The numerical classification of Chrysanthemum flower color phenotype. Acta Hort. Sin. 39(7):1330-1340. (in Chinese).

Hosaka, H., T. Mizuno, and T. Iwashina. 2012. Flavonoid pigments and color expression in the flowers of black Hollyhock (Alcea rosea 'nigra'). Bull. Natl. Mus. Nat. Sci. 38:69-75.

Hughes, N.M., H.S. Neufeld, and K.O. Burkey. 2006. Functional role anthocyanins in highlight winter leaves of the evergreen herb Galax urceolata. New Phytol. 168:575-587.

Jia, N., Q.Y. Shu, L.S. Wang, H. Du, Y.J. Xu, and Z.A. Liu. 2008. Analysis of petal anthocyanins to investigate coloration mechanism in herbaceous peony cultivars. Scientia Hort. 117:167173.

Jin, X.H., H. Huang, L. Wang, Y. Sun, and S.L. Dai. 2016. Transcriptomics and metabolite analysis reveals the molecular mechanism of anthocyanin biosynthesis branch pathway in different Senecio cruentus cultivars. Front. Plant Sci. 7(107):1307.

Kumi, Y., M. Mihoko, and K. Tadao. 2009. Blue flower color development by anthocyanins: From chemical structure to cell physiology. Nat. Prod. Rep. 26(7):884-915.

Lewis, D.H., H.S. Arathoon, E.E. Swinny, S.C. Huang, and K.A. Funnell. 2003. Anthocyanin and carotenoid pigments in spathe tissue from selected Zantedeschia hybrids. Acta Hort. 624:147-154.

Li, C.H., L.S. Wang, Q.Y. Shu, Y.J. Xu, and J. Zhang. 2008. Pigments composition of petals and floral color change during the blooming period in Rhododendron mucronulatum. Acta Hort. Sin. 35(7):1023-1030.

Li, Q., J. Wang, H.Y. Sun, and X. Shang. 2014. Flower color patterning in pansy (Viola $\times$ wittrockiana Gams) is caused by the differential expression of three genes from the anthocyanin pathway in acyanic and cyanic flower areas. Plant Physiol. Biochem. 84:134141.

Merzlyak, M.N., O.B. Chivkunova, A.E. Solovchenko, and K.R. Naqvi. 2008. Light absorption by anthocyanins in juvenile, stressed, and senescing leaves. J. Expt. Bot. 59(14):3903-3911.

Mizuta, D., T. Ban, I. Miyajima, A. Nakatsuka, and N. Kobayashi. 2009. Comparison of flower color with anthocyanin composition patterns in evergreen Azalea. Scientia Hort. 122(4): 594-602.

Mol, J., E. Grotewold, and R. Koes. 1998. How genes paint flowers and seeds. Trends Plant Sci. 3:212-217.

Nielsen, K.M., D.H. Lewis, and E.R. Morgan. 2003. Characterization of carotenoid pigments and their biosynthesis in two yellow flowered lines of Sandersonia aurantiaca (Hook). Euphytica 130(1):25-34.

Noda, K., B. Glover, P. Linstead, and C. Martin. 1994. Flower colour intensity depends on specialized cell shape controlled by a Mybrelated transcription factor. Nature 369:661664.

Paech, K. 1955. Colour development in flowers. Organization 12(6):401-435.

Qi, Y., L. Qian, H. Li, J. Yue, Y. Liu, and Y. Wang. 2013. Anatomical and biochemical studies of bicolored flower development in Muscari latifolium. Protoplasma 250(6):1273-1281.

Rasika, G.M., R.K. Adelheid, and D.A. Teresita. 2003. Pigment distribution and epidermal cell shape in Dendrobium species and hybrids. HortScience 38:573-577.

Singh, Y., A.E.V. Wyk, and H. Baijnath. 1996. Floral biology of Zantedeschia aethiopica (L). spreng. (Araceae). S. Afr. J. Bot. 62(3):146150 .

Stobiecki, M. 2000. Application of mass spectrometry for identification and structural studies of flavonoid glycosides. Phytochemistry 54(3): 237-256.

Sun, W., C.H. Li, L.S. Wang, and S.L. Dai. 2010. Accumulation and variation of anthocyanins in blue flowers of Senecio cruentus at different flowering stages. Beijing Fore Univ. 35(7): 1023-1030.

Sun, W., C.H. Li, L.S. Wang, S.L. Dai, and Y.J. Xu 2009. Anthocyanins present in flowers of $\mathrm{Se}$ necio cruentus with different colors. Acta Hort. Sin. 36:1775-1782.

Voss, D.H. 1992. Relating colorimeter measurement of plant color to the royal horticultural society colour chart. HortScience 27:1256-1260.

Wang, L.S., F. Hashimoto, A. Shiraishi, N. Aoki, J.J. Li, and Y. Sakata. 2004. Chemical taxonomy of the xibei Tree peony from china by floral pigmentation. J. Expt. Bot. 117:47-55.

Wang, L.S., A. Shiraishi, F. Hashimoto, N. Aoki, K. Shimizu, and Y. Sakata. 2001. Analysis of petal anthocyanins to investigate flower coloration of zhongyuan (chinese) and daikon island (japanese) tree peony cultivars. J. Expt. Bot. 114:33-43.

Williams, C.A., J.B. Harborne, and S.J. Mayo. 1981. Anthocyanin pigments and leaf flavonoids in the family Araceae. Phytochemistry 20:217-234.

Yamagishi, M. and K. Akagi. 2013. Morphology and heredity of tepal spots in asiatic and Oriental lilies (Lilium spp.). Euphytica 194(3): 325-334.

Yamagishi, M., H. Ihara, K. Arakawa, S. Toda, and K. Suzuki. 2014. The origin of the lhmyb12, gene which regulates anthocyanin pigmentation of tepals, in Oriental and Asiatic hybrid lilies (Lilium spp.). Scientia Hort. 174(1):119125.

Yasuda, Q. 1989a. In: Y.L. Fu (ed.). Flower color physiology biochemistry, p. 9-51. Trans. China For. Publ. House, Beijing, China.

Yasuda, Q. 1989b. In: Zhan and Z.C. Tong (eds.). The mystery of flower color, p. 31-50. Trans. China For. Publ. House, Beijing, China.

Yoshitama, K. 1981. Caffeic acid 4- $\beta$-glucoside as the acyl moiety of the Senecio cruentus, anthocyanin. Phytochemistry 20(1):186-187.

Zhang, J.J., L.S. Wang, Q.Y. Shu, Z.A. Liu, C.H. Li, J. Zhang, X.L. Wei, and D.K. Tian. 2007. Comparison of anthocyanins in non-blotches and blotches of the petals of xibei tree peony. Scientia Hort. 114(2):104-111.

Zhang, J.L., D.R. Pan, Y.F. Zhou, Z.C. Wang, S.M. Hua, L.L. Hou, and F.F. Sui. 2009. Cloning and expression of genes involved in anthocyanins synthesis in ornamental sunflower. Acta Scientia Hort. 36(1):73-80.

Zhang, Y., J.Y. Wu, Y.N. Wu, M.W. Tang, and L.N. Xie. 2016. Progresses and perspective of the function of MYB transcription factor MIXTA and its Orthologous gene. Scientia Agr. Sin. 49(7):1230-1241.

Zhao, C., W. Guo, and J. Chen. 2004. Preliminary study on the categories and contents of the flower color pigments of Prunus mume sieb et zucc. J. Beijing For. Univ. 26(2):68-73.

Zhao, D.Q., M.R. Wei, D. Liu, and J. Tao. 2016. Anatomical and biochemical analysis reveal the role of anthocyanins in flower coloration of herbaceous peony. Plant Physiol. Biochem. 102:97-106. 


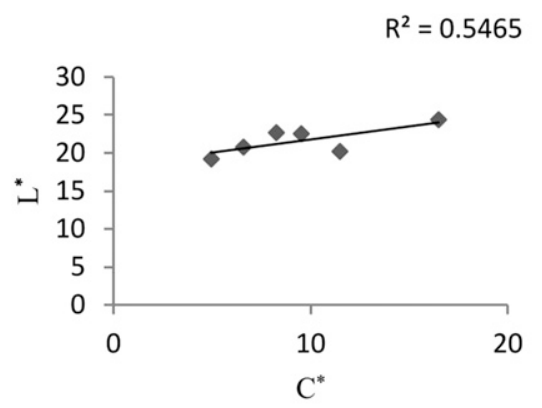

Black group

$R^{2}=0.228$

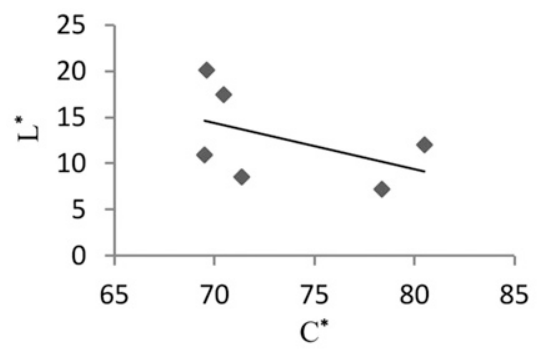

Pink group

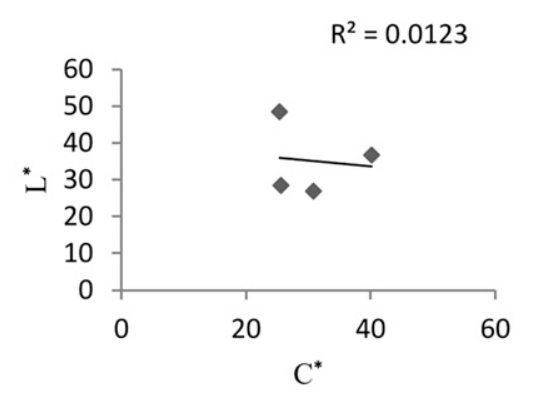

Amaranth group

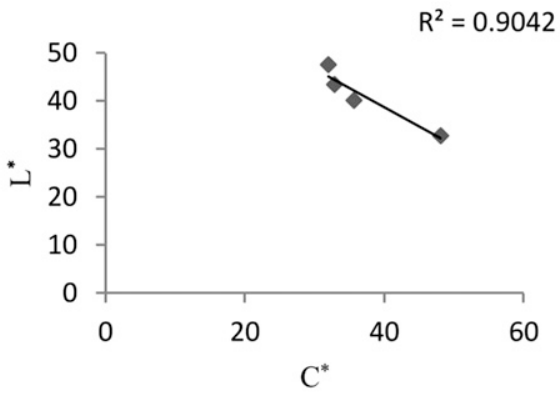

Red group

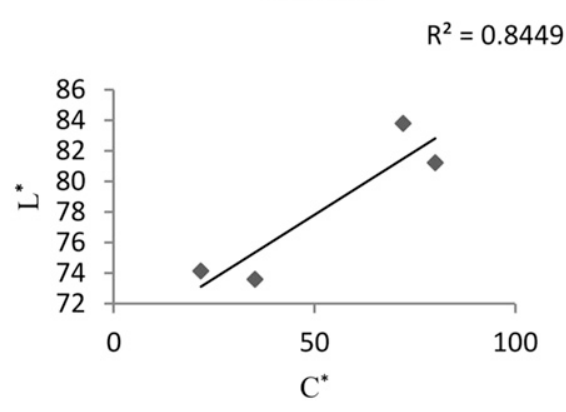

Yellow group

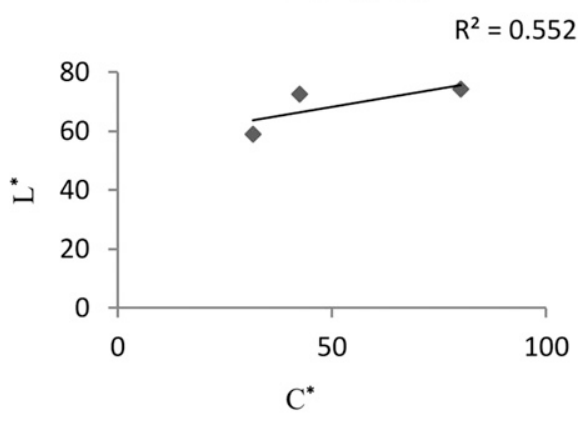

Orange group

Supplemental Fig. 1. Relationships between redness (or yellowness) and total anthocyanin (or total flavones and flavonols) of $Z$. hybrida each color group. 

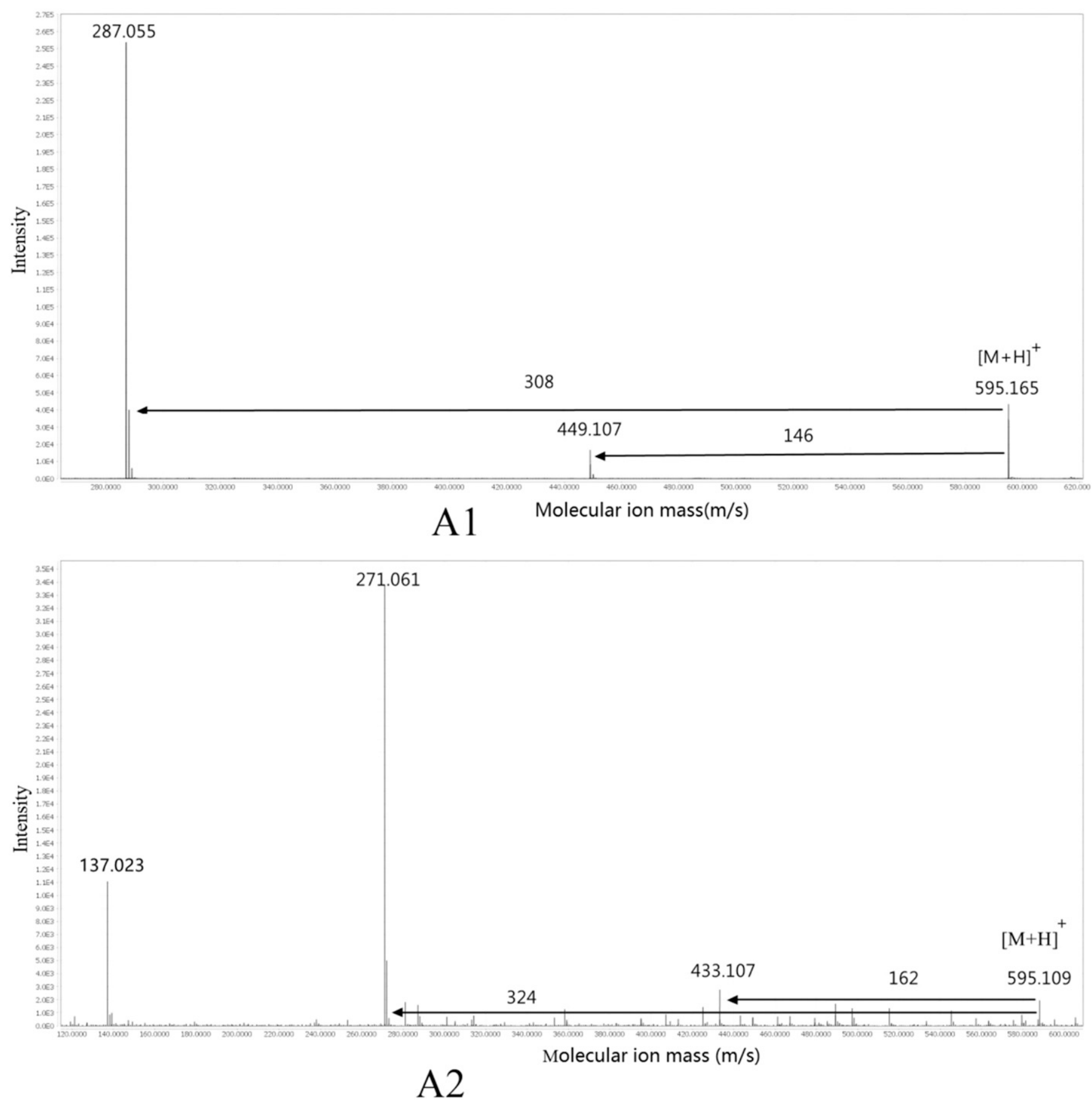

Supplemental Fig. 2. The mass spectra of anthocyanin A1, A2. 


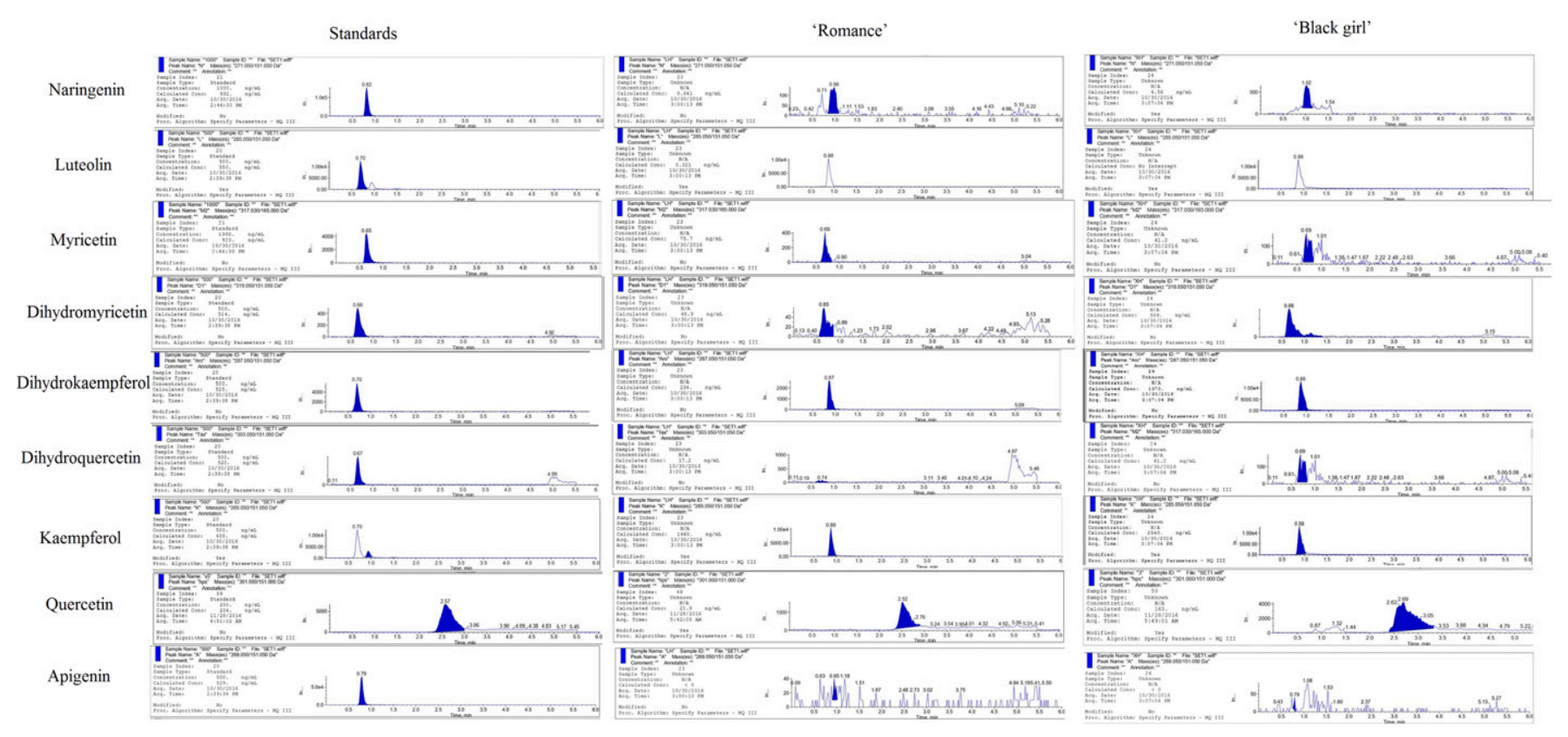

Supplemental Fig. 3. Ultra-performance liquid chromatography of flavones and flavonols in Z. hybrida. 

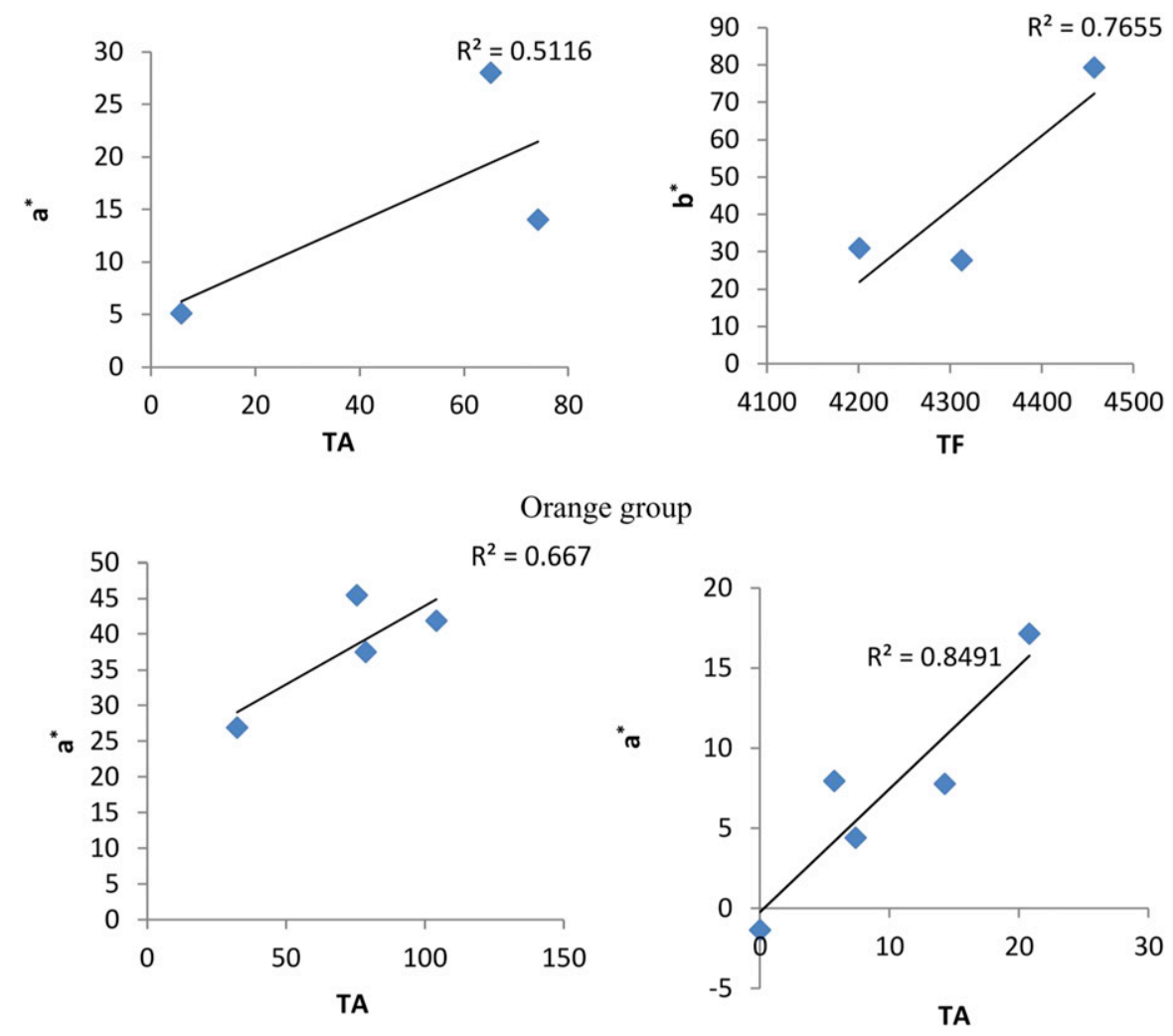

Red group

Pink group

Supplemental Fig. 4. Relationships between redness $\left(a^{*}\right)$ and total anthocyanin (TA) [or total flavones and flavonols (TF)] among of $Z$. hybrida. 